\section{Olive Pit Pyloric Obstruction}

Most ingested foreign bodies pass through the gastrointestinal tract without incident (1). Although it has been reported that organic strictures can cause complete obstruction even with normal food (2), obstruction of a peptic pyloric stricture by an ingested olive pit has not apparently been reported previously.

Recently, a 40-year-old man underwent gastroscopy for presumed gastric outlet obstruction, accompanied by melena. Almost complete pyloric obstruction caused by a chronic ulcer was found, with hematin seen in the ulcer base (Forrest grade 2d). Subsequently, the patient underwent an emergency two-thirds gastrectomy for continuing hemorrhage, and when the resected specimen was opened, the severely scarred pyloric channel was found to be totally obstructed by an olive pit (Figure 1). The olive pit was a tarry black color, thus strongly resembling hematin in the ulcer base. After surgery, the patient explained that he had ingested several olive pits, following an ancient Bulgarian superstition according to which "ingested olive pits can cure peptic ulcer disease."

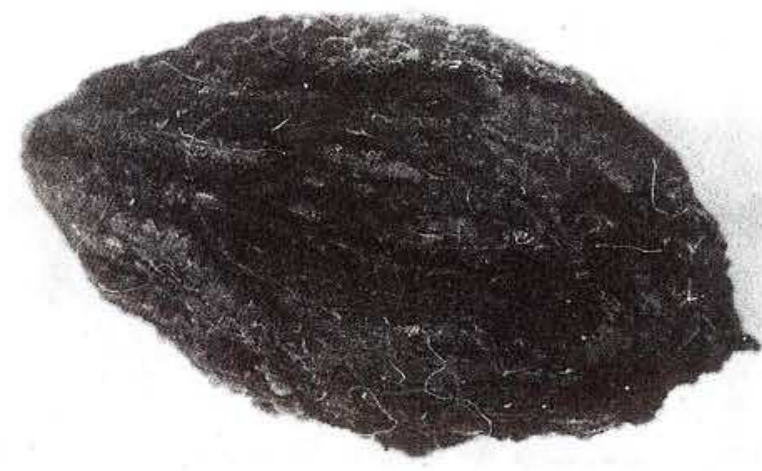

Figure 1: The olive pit after surgical removal. Note the roughness of the surface. The bar is not seen on this reproduction of the original glossy print.

Recurrent episodes of foreign body ingestion may occur as a result of health faddism (3). Obviously, in patients with peptic gastric outlet obstruction, even a single apparently innocent foreign body may cause total occlusion of the severely scarred pyloric channel. With the recent substantial increase in travel from eastern Europe, due to both tourism and immigration, similar cases may be observed 
abroad in the future as well, and physicians should therefore be aware of this. We believe that, when there is a high degree of suspicion, the slight roughness of the olive pit's surface can be reliably observed endoscopically, allowing timely discovery of this unusual cause of gastric outlet obstruction.

J. E. Losanoff, K. T. Kjossev, H. E. Losanoff

Dept. of Emergency Surgery, Military Medical Academy, Sofia, Bulgaria

\section{References}

1. Webb WA. Management of foreign bodies of the upper gastrointestinal tract. Gastroenterology 1988; 94: 204-16.
2. Claman MA. Acute intestinal obstruction caused by food. Arch Surg 1963; 87: 422-3.

3. Hsu HH, Groove WE, Mindultun R, Knauer CM. Gastric bezoar caused by lecithin: an unusual complication of health faddism. Am J Gastroenterol 1992; 87: 794-6.

Corresponding Author

J. E. Losanoff, M.D.

Dept. of Emergency Surgery

Military Medical Academy

P.O. Box 159

1606 Sofia

Bulgaria 